\title{
The Simultaneous Vehicle Scheduling and Passenger Service Problem
}

\author{
Petersen, Hanne Løhmann; Larsen, Allan; Madsen, Oli B.G.; Røpke, Stefan
}

Publication date:

2010

Link back to DTU Orbit

Citation (APA):

Petersen, H. L., Larsen, A., Madsen, O. B. G., \& Røpke, S. (2010). The Simultaneous Vehicle Scheduling and Passenger Service Problem. Abstract from Tristan VII: Seventh Triennial Symposium on Transportation Analysis, Troms $\varnothing$, Norway.

\section{General rights}

Copyright and moral rights for the publications made accessible in the public portal are retained by the authors and/or other copyright owners and it is a condition of accessing publications that users recognise and abide by the legal requirements associated with these rights.

- Users may download and print one copy of any publication from the public portal for the purpose of private study or research.

- You may not further distribute the material or use it for any profit-making activity or commercial gain

- You may freely distribute the URL identifying the publication in the public portal

If you believe that this document breaches copyright please contact us providing details, and we will remove access to the work immediately and investigate your claim 


\title{
The Simultaneous Vehicle Scheduling and Passenger Service Problem
}

\author{
Hanne L. Petersen ${ }^{1}$, Allan Larsen, Oli B.G. Madsen, Stefan Røpke \\ Department of Transport \\ Technical University of Denmark, Kgs. Lyngby, Denmark \\ ${ }^{1}$ Email: hlp@transport.dtu.dk
}

\section{Problem description}

Passengers using public transport systems often experience waiting times when transferring between two scheduled services. We propose a planning approach which seeks to obtain a favourable trade-off between the conflicting objectives of operating cost and quality of passenger service as part of the vehicle scheduling process for such systems.

The well-known Vehicle Scheduling Problem (VSP) is concerned with determining a set of vehicle schedules to operate a given timetable at the lowest possible cost. This problem is often encountered within bus operation in public transport.

The Simultaneous Vehicle Scheduling and Passenger Service Problem is based on the VSP, with two significant modifications: First, the trips of the timetable are allowed to be shifted by a few minutes to an earlier or later departure time, in the hope that this increased flexibility can lead to a lower operating cost, without introducing significant changes to the timetable. Secondly, a measure of passenger service is introduced for the evaluation of solutions, in order to control the effects of this timeshifting.

The measure of passenger service used in the calculations is based on the passenger waiting times at transfers between different lines. These transfers can take place between two lines that are both under the control of the model (and thereby have varying departure times), or to/from a line that is external to the model (and thereby has a fixed timetable). It should also be noted that passenger waiting times considered in this work, are only waiting times at transfers and not those experienced by passengers entering the system.

An application from the Greater Copenhagen Area is studied, dealing with the network of local express buses, which is build up around the local train network. A schematic overview of this network can be seen in Figure 1, where the dashed lines represent train lines (roughly with the 
form of a fan), and the solid lines (all shades) show the available bus lines, of which most are perpendicular to the train lines.

The SVSPSP takes as input existing timetables and data regarding passenger flow at transfer points. For the SVSPSP these passenger flows are assumed to be fixed and independent of the operated timetables. The set of input timetables dictates the required level of service, and the number of departures is unchanged by the solution. Additionally, each departure can only be timeshifted by a limited number of minutes, meaning that the overall distribution of departures over the span of the day is not changed significantly.

To the authors' knowledge, no existing literature deals with a problem identical to the SVSPSP, and few similar problems have been treated, integrating vehicle scheduling and timetabling problems. The integration of timetabling and multi-depot vehicle scheduling is studied in [2] with the aim of reducing costs (reducing the number of vehicles) while ignoring passenger waiting times. The approach allows the trip starting times for each line to be timeshifted to allow greater flexibility in the vehicle scheduling part. The paper presents integer programming models as well as a local search algorithm that solves a network flow problem in each local search iteration. [1] also integrates vehicle scheduling and timetable synchronisation in an optimisation problem. The authors consider several terms in the objective function: number of vehicles required, number

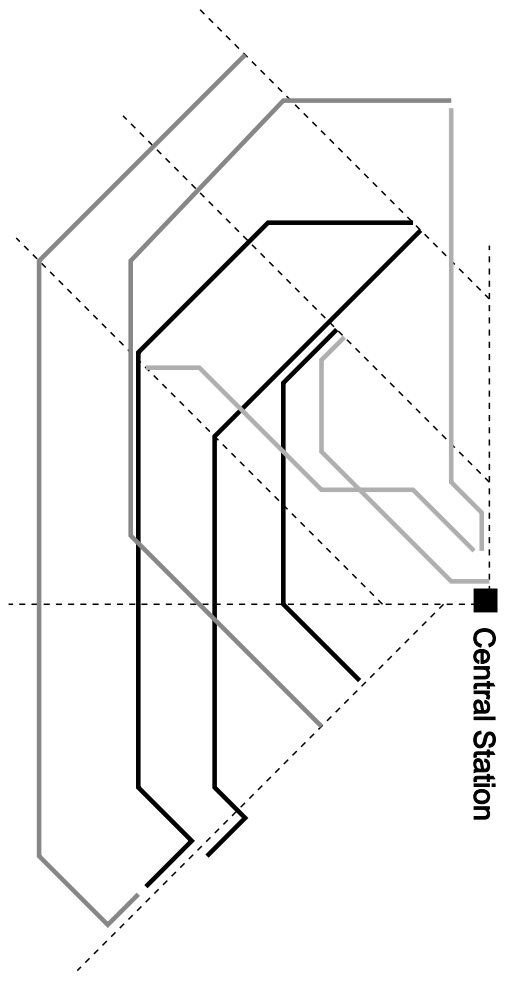

Figure 1: The structure of the overall public transportation network in the Greater Copenhagen Area and quality of transfer possibilities and the so-called headway evenness. The second term aims at minimising passenger inconvenience, while the last term attempts to make regular arrivals on each line. These three terms are weighted together.

\section{Data issues}

The problem has been solved on a dataset derived from real-life data from the Greater Copenhagen Area, providing the geographic information and route networks. The currently operated train timetables have been used as fixed input, and the current bus timetables have been used as the starting point for the solution.

Real-life data regarding numbers of (dis)embarking passengers at each stop are unfortunately 
not available at present, and have instead been estimated depending on line, location, and time of day. Furthermore, a percentage distribution of (dis)embarking passengers among lines available for transfer has been estimated. Finally, the combination of these numbers has led to the number of transferring passengers at each existing connection.

The units of the different objectives (operating cost and passenger waiting time) have been combined by conversion to a common monetary unit, by using the value of travel time recommended by the Danish Ministry of Transport.

\section{Solution and results}

The SVSPSP has been solved using a Large Neighbourhood Search (LNS) approach [3], where the initial solution is constructed using a greedy VSP heuristic on the existing timetable. The destroy operator removes trips either at random, or based on similarity with previously removed trips, where the measure of similarity is based on shared trip end points or proximity in time. At insertion each trip may be timeshifted with a certain percentage, and the procedure is then based on a cheapest insertion principle. The acceptance criterion for a new solution is based on simulated annealing.

The solution algorithm has been tested on instances of 3 different sizes based on subsets of increasing size of the real-life data. First a "small" instance, containing 3 bus lines (black in Figure 1), which all have quite many (5-6) intersections with the train network, but few connections between buses. These lines have a rather high passenger intensity, and a total of 538 trips per day. The "medium" instance contains 5 bus lines and is a superset of the small instance (black and dark grey in Figure 1), with on average slightly fewer intersections with the train network, and not quite as many passengers (792 trips per day). Finally, the "large" set contains all 8 bus lines that are in current operation in the real-life dataset, with a mixture of transfers to trains and buses and a total of 1400 trips per day.

\begin{tabular}{lrrrr} 
& cost red. & empty & time & shifts \\
\hline 3 lines & $3.3 \%$ & $-8.9 \%$ & $18.1 \%$ & $73.8 \%$ \\
5 lines & $3.2 \%$ & $-7.8 \%$ & $22.5 \%$ & $78.2 \%$ \\
8 lines & $2.0 \%$ & $-7.1 \%$ & $16.4 \%$ & $76.4 \%$ \\
\hline
\end{tabular}

Table 1: Solution improvements for different problem sizes

Table 1 summarises the results obtained by running the LNS heuristic for 24 hours, with reductions compared to a reference solution obtained using the same heuristic without allowing timeshifting. The table shows the total cost reduction, the reduction in empty mileage (a negative reduction indicating that empty mileage has increased), the reduction in passenger waiting time, 
and the number of trips that have been timeshifted.

The total cost that is considered in the table is a combination of operating cost and cost of passenger waiting time, and the results show that a certain reduction of this cost $(2-3 \%)$ can be obtained by the suggested solution procedure. This happens at the expense of empty mileage (increasing by 7-9\%), but leads to a considerable reduction of passenger waiting time at transfers. Finally, we can see that around $75 \%$ of all trips have been timeshifted in the final timetable, indicating that timeshifting certainly has an impact.

Furthermore, we can consider the degree of "memorability" of the obtained solutions, which we use to express that the timetable is easier for passengers to remember if buses depart at regular intervals. This is appreciated by operators, but has not been included in the optimisation. For the solutions reported above, the memorability is in the range $35-50 \%$, which is a considerable reduction in comparison to the reference solution, where these values are in the range $72-84 \%$.

\section{Further work}

Some suggestions for further work on the problem presented here would be twofold; first, it could be interesting to obtain better data for the passenger movements in the case study, and second, some improvements concerning the solution procedure are possible.

In particular, the SVSPSP could be treated as a multiobjective problem, regarding the operating cost and passenger waiting time as separate objectives, for example by considering the improvement of passenger waiting time, that can be obtained by limiting the allowed increase of total operating cost (possibly to zero).

Furthermore, the memorability of a solution could be considered an additional objective and added to the solution procedure. The results so far indicate that this value does indeed deteriorate under the current solution approach.

\section{References}

[1] V. Guihaire, J.-K. Hao, "Transit Network Re-Timetabling and Vehicle Scheduling", Communications in Computer and Information Science 14, 135-144 (2008).

[2] A. van den Heuvel, J. van den Akker, M. van Koten Niekerk, "Integrating timetabling and vehicle scheduling in public bus transportation", Technical Report, Department of Information and Computing Sciences, Utrecht University, 2008.

[3] P. Shaw, "Using constraint programming and local search methods to solve vehicle routing problems", CP-98 (Fourth International Conference on Principles and Practice of Constraint Programming) 1520, 417-431 (1998). 